\title{
AVALIAÇÃO SANITÁRIA DO LÍQUIDO PERCOLADO EM ÁREA IRRIGADA COM EFLUENTE ANAERÓBICO
}

\author{
HEALTH ASSESSMENT IN PERCOLATED LIQUID IN AREA IRRIGATED WITH \\ ANAEROBIC EFFLUENT
}

\author{
Saulo Bruno S. e Souza ${ }^{1}$; Coraucci Filho, B. ${ }^{2}$, Bertoncini, E. ${ }^{3}$; Stefanutti, R. ${ }^{4}$; Figueiredo, R. F. ${ }^{5}$
}

Recebido em 28 de novembro de 2010; recebido para revisão em 29 de dezembro de 2010; aceito em 16 de janeiro de 2011; disponivel on-line em 07 de fevereiro de 2011

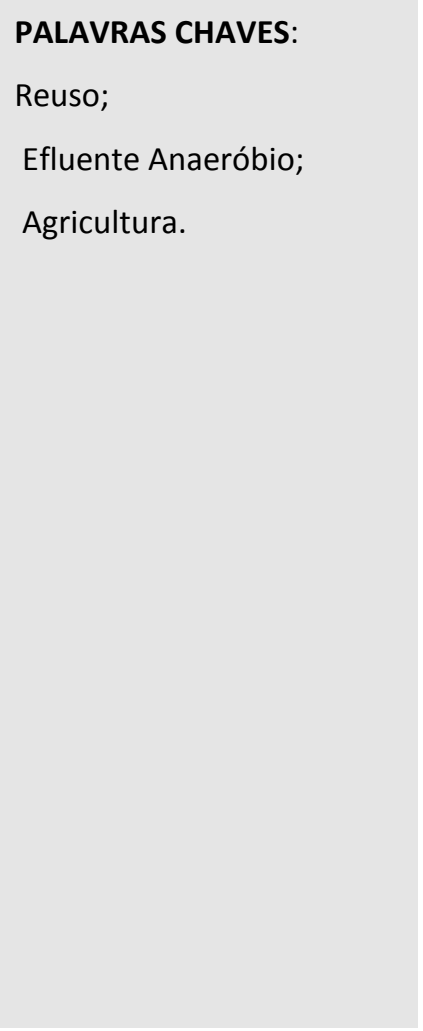

\begin{abstract}
RESUMO: O reuso de efluente na agricultura surge como uma ótima alternativa de destino para o efluente tratado, visto que este pode fornecer água, matéria orgânica, e nutrientes vantajosos para as plantas, ao mesmo tempo em que possui concentrações que extrapolam os padrões de lançamento. Neste estudo o reuso do efluente resultante de tratamento em uma lagoa anaeróbia foi feito por meio de um sistema de irrigação por sulcos rasos, tendo como principal objetivo a determinação de taxas de aplicação no solo, que sejam convenientes do ponto de vista sanitário e agronômico, à proteção dos aqüíferos subterrâneos e à produção de colheitas. Para tanto, foram investigadas três lâminas hídricas correspondentes às profundidades de irrigação de $0,20,0,40$ e $0,60 \mathrm{~m}$. O estudo sanitário foi realizado pela coleta de lixiviados de solução do solo extraídas de coletores instalados nas profundidades de 0,25, 0,50 e 0,75 m, e nos quais foram avaliadas as concentrações de nitrato e os parâmetros DBO e DQO. O solo utilizado foi o Argissolo Vermelho-Amarelo, textura média, e os tratamentos contemplaram parcelas irrigadas com efluente e parcelas irrigadas com água e fertilizadas com adubo químico. Empregou-se a cultura do milho (Zea mays) cultivar AG405 durante as safras de verão (estação chuvosa), e de inverno (estação seca), para avaliar a eficiência do sistema Os valores médios obtidos para os coletores de drenagem para DBO indicam uma redução de cerca de $94 \%$ em relação ao efluente anaeróbio aplicado na irrigação, com os valores variando de 0,5 a $22,7 \mathrm{mg} \mathrm{L}^{-1}$. Para os valores médios de DQO, observa-se uma redução de cerca de $95 \%$ quando comparado aos resultados do efluente anaeróbio. A medida em que se aumenta a profundidade dos coletores observa-se uma redução crescente nestes valores, como esperado.
\end{abstract}

* Contato com os autores:

${ }^{1}$ e-mail: saulobruno@yahoo.com.br (S.B.S.Souza)

Prof. MSc Engenharia Civil - Universidade Federal de Goiás

2e-mail: bruno@fec.unicamp.br (B. Coraucci)

Prof. Dr. Livre Docente - FEAGRI - UNICAMP

ISSN: 2179-0612

(C) 2011 REEC - Todos os direitos reservados.

\section{INTRODUÇÃO}

O reuso de efluentes domésticos na agricultura surge como uma ótima alternativa de destino para o efluente tratado, visto que este possui características vantajosas para a agricultura, ao mesmo tempo em que possui concentrações que extrapolam os padrões de lançamento nos cursos d'água. Além disso, o reuso agrícola funciona como um sustentáculo para 
regiões onde a falta de água já é uma realidade, como a região sudeste do Brasil. $O$ uso de efluente de tratamento de esgoto na irrigação aumenta a oferta hídrica para aplicação na agricultura, além de reduzir a demanda de água para estes fins, visto que atualmente cerca de $70 \%$ do consumo de água no mundo se deve ao uso para irrigar culturas agrícolas.

Em regiões áridas e semi-áridas, como Israel, Líbano e países vizinhos, a irrigação com efluentes proporciona a redução do consumo agrícola da água, havendo um melhor compartilhamento da água para abastecimento humano com a irrigação das colheitas. Friedler (1999), registra que, num futuro próximo, em Jeezrael Valley, Israel, a irrigação com efluente será correspondente a $80 \%$ de toda a irrigação local. O nordeste brasileiro também sofre com situação similar. O Brasil é um país que apresenta alto potencial para a adoção da técnica de reuso com aplicação em irrigação, pois possui vastas áreas agrícolas, e necessita tratar seus efluentes com técnicas alternativas de baixo custo. Logo, o reuso de águas resíduarias na agricultura pode trazer sustentabilidade tanto no pós-tratamento de efluentes como no aumento da produtividade agrícola.

O sistema de tratamento anaeróbio seguido de pós-tratamento no solo é considerado um processo de baixo custo e com pouco consumo de energia, garantindo um nível satisfatório comparável ao tratamento terciário, além de fornecer água e nutrientes às plantas, retorno de elementos ao seu ciclo biogeoquímico, e minimiza os conflitos dos usos múltiplos da água.

O uso de efluentes de esgoto doméstico em solos, proporciona a incorporação de macronutrientes $(\mathrm{N}, \mathrm{P}, \mathrm{K}, \mathrm{Ca}, \mathrm{Mg}, \mathrm{S})$ e micronutrientes ( $\mathrm{Cu}$ e $\mathrm{Zn}$ ) de plantas aos solos. A adição de matéria orgânica promove a estruturação e melhoria das características físicas do solo, reduzindo sua susceptibilidade a erosão, além de aumentar a atividade biológica do solo, a resistência das plantas a patógenos e pragas, e de melhorar o poder tampão de solos, contribuindo na retenção de poluentes, como pesticidas e metais pesados. Entretanto, a aplicação de efluentes no solo não deve ser feita de forma indiscriminada, e sem monitoramento. Deve existir um elo perfeito entre os critérios de projetos da engenharia sanitária e os da engenharia agronômica, de forma que o efluente possa ser aplicado e tratado no solo sem que haja sua contaminação e sua saturação por nutrientes.

O lençol freático também merece grande atenção para que não receba cargas de contaminantes, como nitratos, metais pesados e patógenos oriundos do esgoto doméstico. Logo, é extremamente importante um estudo detalhado e confiável que forneça subsídios para a escolha de uma cultura adequada, bem como as taxas hidráulicas de irrigação e os turnos de rega para que as condições sanitárias sejam respeitadas (Vieira, 1999).

Na literatura são escassos os relatos sobre o potencial contaminante que tal sistema possui sobre o lençol de água subterrâneo. Neste aspecto, o objetivo deste trabalho é de monitorar a concentração de DQO e DBO ao longo do perfil dos solos tratados com efluente de esgoto tratado em lagoa anaeróbia. Conforme a Portaria 518/2004, do Ministério da Saúde, a concentração máxima de nitrato em água potável, para consumo humano é de $10 \mathrm{mg} \mathrm{L}^{-1}$. De acordo com a resolução CONAMA 357/2005, para as águas doces das classes de 1 a 4, o limite máximo permitido de nitratos também é de $10 \mathrm{mg} \mathrm{L}^{-1}$, enquanto na classe especial o nitrato e a amônia devem estar ausentes. A remoção de sólidos totais também não deve atinge os valores de 100 $\mathrm{mg} \mathrm{L}^{-1}$, conforme recomendado pela literatura. Ainda, a ETE deve possuir eficiência mínima na remoção de carga orgânica de $80 \%$.

O objetivo deste trabalho foi estudar o decaimento do carbono orgânico em três profundidades do perfil de solo irrigado com efluente de tratamento de esgoto, e cultivado com milho, nas estações de verão e inverno, de modo a viabilizar sua aplicação mais segura por meio de um processo de irrigação.

\section{MATERIAL E MÉTODOS}

A área de estudo localiza-se no município de Limeira, o qual está situado a $154 \mathrm{~km}$ da capital, na região sudeste do estado de São Paulo, a $22^{\circ} 33^{\prime} 45^{\prime \prime}$ de latitude Sul e $44^{\circ} 24^{\prime} 09^{\prime \prime}$ de latitude Oeste, na altitude 570 metros. O Município ocupa a área de $597 \mathrm{~km}^{2}$ e encontra-se a $567 \mathrm{~m}$ do nível do mar entre os rios MogiGuaçu e Piracicaba, na bacia hidrográfica do rio Piracicaba e na sub-bacia do ribeirão Tatu, pertencendo ao sistema hidrográfico Tietê-Paraná.

O projeto foi desenvolvido em uma área experimental que possui uma área de 7978,07 $\mathrm{m}^{2}$, fazendo divisa com a Estação de Tratamento de Esgotos Graminha (ETE - Graminha), pertencente à empresa Águas de Limeira S.A., em Limeira/SP (Figura 1).

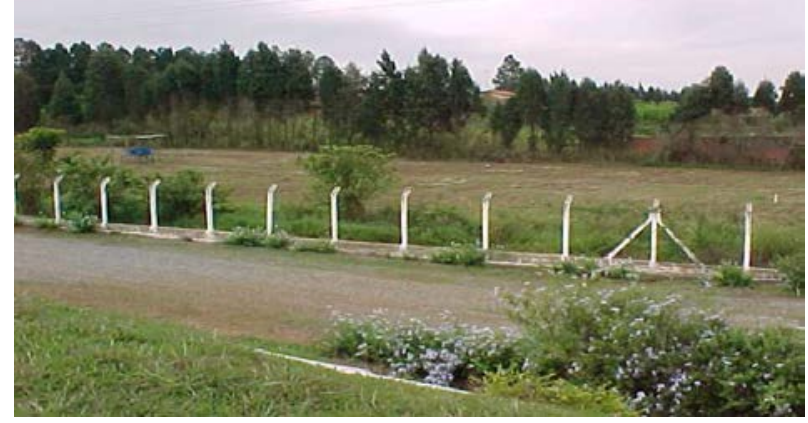

Figura 1: Local de realização da pesquisa

Preliminarmente foram realizados os ensaios físicos do solo, ensaios de fertilidade e levantamento topográfico do terreno, com o intuito de caracterizar a área e levantar parâmetros necessários para o dimensionamento do sistema de irrigação.

Dentre os ensaios físicos, constam determinações da densidade real (Dr), da densidade 
global (Dg), do levantamento da curva característica e da curva granulométrica A coleta de solo foi realizada em três locais distintos, nas camadas de 0,00 - 0,25 m, $0,25-0,50 \mathrm{~m}, 0,50-0,75 \mathrm{~m}, 0,75-1,00 \mathrm{~m}$. O ensaio da densidade real foi feito pelo método do picnômetro. 0 ensaio da densidade global, ou peso específico aparente, foi realizado com o auxílio do amostrador de Uhland (Vieira, 1995). Na região prevalece o solo latossolo vermelho-amarelo, cuja recomendação da taxa de irrigação indicada pela EPA (1981) está entre 0,22 a 1,17 L. s $^{-1}$.ha ${ }^{-1}$, sendo possível estimar que ela se encontre entre 0,5 a 1,0 L.S ${ }^{-1} \cdot$ ha $^{-1}$.

O levantamento da curva granulométrica foi realizado pela análise granulométrica conjunta, a qual é composta de duas fases de ensaio que são: peneiramento e sedimentação. A determinação da curva característica para cada camada de solo foi feita pela aplicação de pressões entre 0,1 bar, correspondente a capacidade de campo (CC), e 15 bar, relativo a ponto de murchamento (PM), no aparelho de Richards.

A coleta de amostras para o ensaio de fertilidade do solo foi baseada em uma amostra composta representativa de solo, referente à coleta em quinze pontos distintos do terreno nas profundidades de $0,00-0,10 \mathrm{~m}, 0,00-0,20 \mathrm{~m}, 0,20-0,40 \mathrm{~m}, 0,40-0,60$ $\mathrm{m}, 0,60-0,80 \mathrm{~m}$ e $0,80-1,00 \mathrm{~m}$. O solo foi corrigido conforme recomendações de Raij et al. (1996).

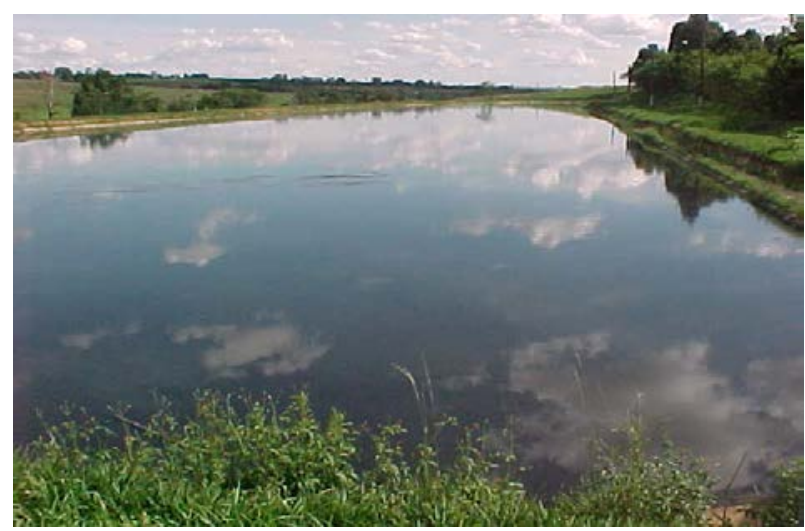

Figura 2: Lagoa anaeróbia que recebe o esgoto doméstico do bairro da Graminha em Limeira/SP.

O efluente aplicado na irrigação é proveniente de uma lagoa anaeróbia, Figura 2, com eficiência de remoção aproximada de $53 \%$ da DBO, que recebe esgoto preponderantemente doméstico de 35 bairros da cidade de Limeira.

O efluente aplicado foi avaliado, determinando-se os parâmetros sanitários de $\mathrm{pH}, \mathrm{DBO}, \mathrm{DQO}$, série dos sólidos, série de nitrogênio, fósforo, segundo Standard Methods for the Examination of Water and Wastewater (1998).

O efluente foi disposto em um sistema de irrigação por sulcos rasos cujas parcelas tem a seguinte configuração: cinco linhas de plantio e quatro sulcos intermediários com 4,0 m de comprimento e 1,0 m de bordadura em cada extremidade.
A distância entre cada linha de cultivo é de 1,0 m. A Figura 3 apresenta o esboço de uma parcela ressaltando os limites de bordadura, e a Figura 4 mostra o modelo implantado.

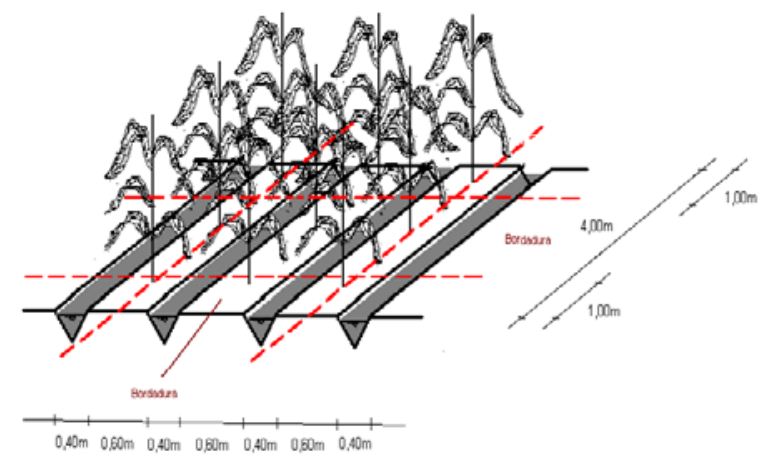

Figura 3: Esquema da parcela, com a identificação das linhas de bordadura e da seção dos sulcos.

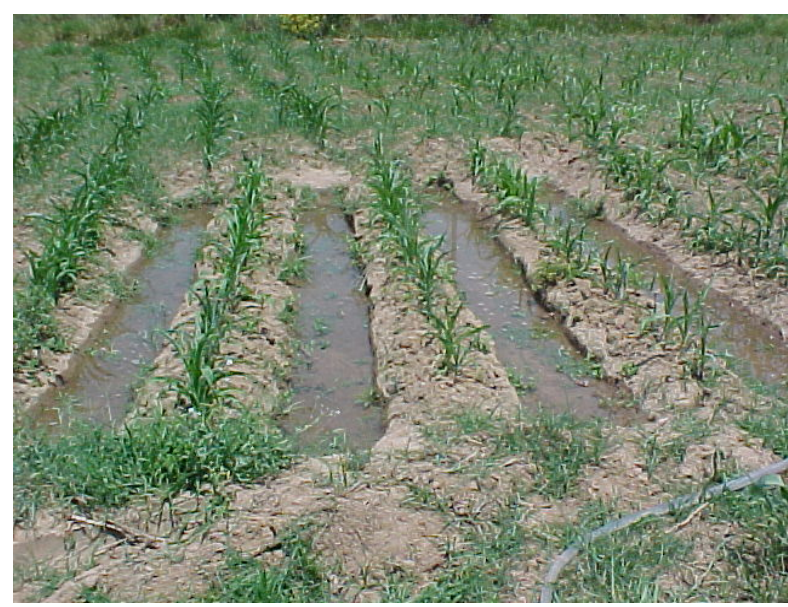

Figura 4: Sistema implantadao.

O sistema de irrigação foi aplicado em dois tratamentos distintos. No tratamento fez-se a irrigação com o efluente secundário e o solo em condições naturais. No segundo, a irrigação foi feita com água limpa em solo enriquecido com nutrientes, segundo resultados analíticos e orientação prestadas pelo Instituto Agronômico de Campinas (IAC).

Para cada tratamento há três parcelas, onde são aplicadas lâminas hídricas (Hi) diferenciadas de irrigação, correspondentes às profundidades de irrigação de 0,20, 0,40 e 0,60 m. A profundidade de irrigação corresponde à profundidade do perfil do solo que se deseja irrigar. Tais valores foram escolhidos em função do cultivo, que, para o caso do milho, é recomendada a profundidade de irrigação de $0,40 \mathrm{~m}$ (Vieira, 1999). A partir deste valor foi escolhida uma profundidade mais conservadora, $0,20 \mathrm{~m}$, e outra menos, 0,60 m.

O conjunto dos dois tratamentos com as três parcelas definem a composição de um bloco, conforme Figura 5. Assim, foi implantado um sistema, o qual é composto por três blocos (para compor o critério de seriação e ser analisado estatisticamente). 
Cada parcela tem quatro sulcos rasos de $4,0 \mathrm{~m}$ de comprimento cada, no interior de cada parcela foram instalados três coletores de drenagem livre a 0,25, 0,50 e $0,75 \mathrm{~m}$ de profundidade. Após a instalação dos coletores, foi executado o plantio de milho.

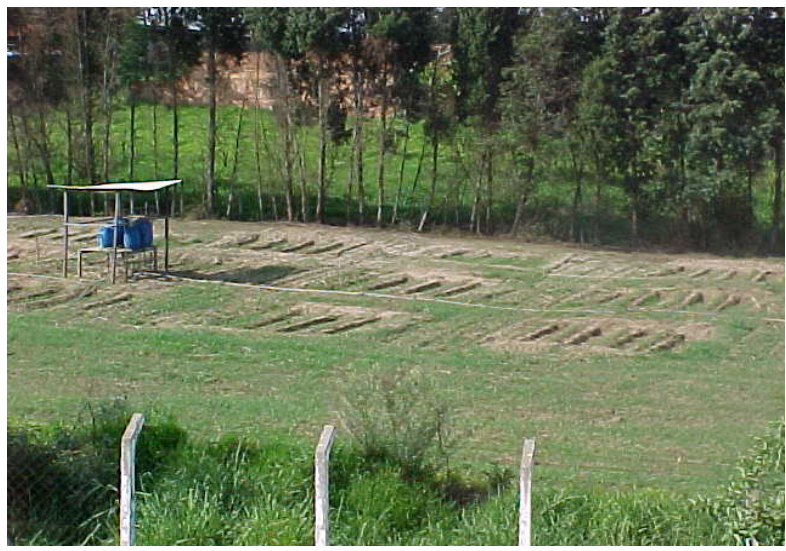

Figura 5: Vista de um bloco implementado, composto pelos três tratamentos.

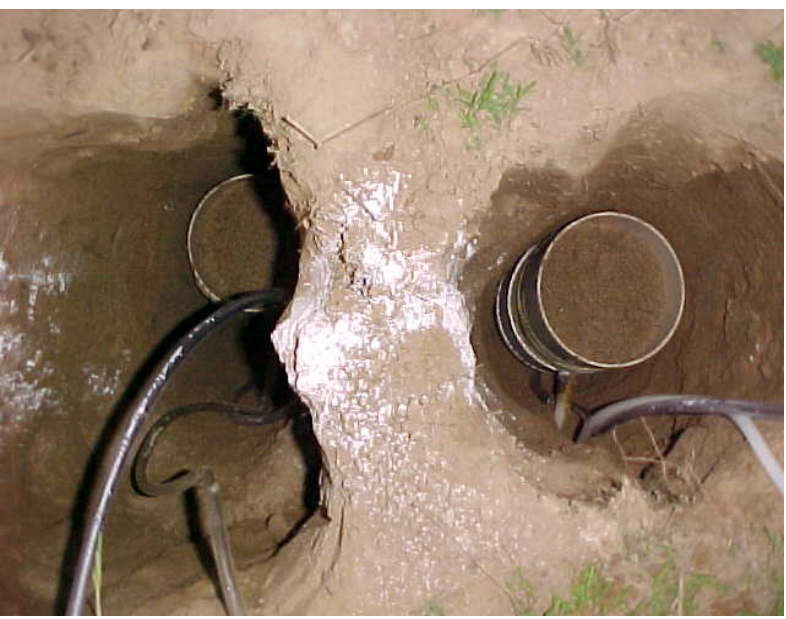

Figura 6: Instalação dos coletores no centro das parcelas, a $0,25,0,50$ e $0,75 \mathrm{~m}$ de profundidade.
O estudo foi desenvolvido para duas safras, em período de estiagem e de chuva, e a freqüência de aplicação ocorreu de acordo com a dotação de rega a ser calculada para as condições do local, com o auxílio dos métodos propostos: o gravimétrico e o tanque Classe A. O manejo da irrigação baseia-se no princípio do fornecimento de água adequado a cultura para sua máxima produtividade agrícola. Para tal, trabalha-se com o teor de água do solo entre a capacidade de campo (CC), ou capacidade máxima de retenção de água no solo, acima da qual o líquido lixivia para o lençol, e com o teor de água crítico (UC), abaixo do qual a planta tem que realizar esforços que comprometem o seu metabolismo para absorver água do solo. Quando o teor de água do solo atinge o valor da UC, irriga-se os sulcos referentes a esta profundidade de irrigação com a lâmina hídrica correspondente, retornando a umidade do solo à capacidade de campo. Foram instalados coletores de drenagem livre (Figura 6) nas profundidades de $0,25 \mathrm{~m}, 0,50 \mathrm{~m}$ e $0,75 \mathrm{~m}$, no centro de cada parcela.

A caracterização do efluente foi realizada a cada aplicação de acordo com Standard Methods for the Examination of Water and Wastewater (1998). A qualidade da água infiltrada no solo, proveniente das parcelas irrigadas com efluente, foi determinada por vários parâmetros, sendo que a concentração de nitrato, e os valores de DBO e DQO receberam destaque neste trabalho.

\section{RESULTADOS E DISCUSSÃO}

A Tabela 1 e 2 nos fornece as taxas hidráulicas empregadas em cada safra, assim como a precipitação pluviométrica do período.

Tabela 1: Caracterização da primeira safra, especificando a precipitação durante os períodos do ciclo vegetativo e as lâminas hídricas empregadas para as profundidades de irrigação de 0,20, 0,40 e 0,60m.

\begin{tabular}{c|c|c|c|c|c|c|c}
$\begin{array}{c}\text { Ciclo } \\
\text { (dias) }\end{array}$ & Período & Ciclo vegetativo & $\begin{array}{c}\text { Ppt máxima no } \\
\text { período }(\mathrm{mm})\end{array}$ & $\begin{array}{c}\text { Soma da ppt no } \\
\text { período }(\mathrm{mm})\end{array}$ & $\begin{array}{c}\text { Lâmina } \\
0,20 \mathrm{~m}\end{array}$ & $\begin{array}{c}\text { Lâmina } \\
0,40 \mathrm{~m}\end{array}$ & $\begin{array}{c}\text { Lâmina } \\
0,60 \mathrm{~m}\end{array}$ \\
\hline $0-35$ & $22 / 04 / 0327 / 05 / 03$ & Inicial & 33,3 & 86,6 & 88,8 & 88,8 & 88,8 \\
\hline $36-97$ & $28 / 05 / 0328 / 07 / 03$ & Desenvolvimento & 0,6 & 0,6 & 148,0 & 172,8 & 181,6 \\
\hline $98-117$ & $29 / 07 / 0317 / 08 / 03$ & Intermediário & 3,8 & 9,6 & 44,4 & 57,6 & 90,8 \\
\hline $118-141$ & $18 / 08 / 0310 / 09 / 03$ & Maturação & 117,3 & 137,8 & 29,6 & 28,8 & 0,0 \\
\hline
\end{tabular}

Tabela 2: Caracterização da segunda safra, especificando a precipitação durante os períodos do ciclo vegetativo e as lâminas hídricas empregadas para as profundidades de irrigação de 0,20,0,40 e 0,60m.

\begin{tabular}{|c|c|c|c|c|c|c|c|}
\hline $\begin{array}{l}\text { Ciclo } \\
\text { (dias) }\end{array}$ & Período & Ciclo vegetativo & $\begin{array}{l}\text { Ppt máxima no } \\
\text { período (mm) }\end{array}$ & $\begin{array}{c}\text { Soma da ppt } \\
\text { no período } \\
(\mathrm{mm})\end{array}$ & $\begin{array}{l}\text { Lâmina } \\
0,20 \mathrm{~m}\end{array}$ & $\begin{array}{l}\text { Lâmina } \\
0,40 \mathrm{~m}\end{array}$ & $\begin{array}{l}\text { Lâmina } \\
0,60 \mathrm{~m}\end{array}$ \\
\hline $0-27$ & $11 / 11 / 03$ 08/12/03 & Inicial & 103,5 & 287,1 & 0,0 & 0,0 & 0,0 \\
\hline $28-68$ & 09/12/03 18/01/04 & Desenvolvimento & 52,1 & 256,4 & 29,6 & 28,8 & 45,4 \\
\hline $69-93$ & $19 / 01 / 04$ 12/02/04 & Intermediário & 39,8 & 118,1 & 29,6 & 28,8 & 45,4 \\
\hline $94-114$ & $13 / 02 / 04$ 04/03/04 & Maturação & 107,7 & 203,5 & 0,0 & 28,8 & 0,0 \\
\hline
\end{tabular}


A Tabela 3 apresenta os resultados da caracterização do efluente aplicado em cada irrigação. Verifica-se que a concentração de nitrogênio total ultrapassa o limite recomendado pela EPA (1992), de 30mg.L-1, para qualidade de água para irrigação.
Também pode ser observado que o efluente tratado em lagoa anaeróbia não se apresenta dentro dos padrões exigidos para lançamento em cursos de água de classe 1, 2 ou até mesmo 3, segundo o CONAMA 357 (2005), devendo passar por pós-tratamento para que seja disposto em corpos de água.

Tabela 3: Caracterização do efluente anaeróbio aplicado em cada safra.

\begin{tabular}{|c|c|c|c|}
\hline \multirow{2}{*}{ Parâmetros } & \multirow{2}{*}{ Bruto } & \multicolumn{2}{|c|}{ Efluente anaeróbio } \\
\hline & & $1^{a}$ safra & $2^{a}$ safra \\
\hline pH (mín.e máx.) & 6,5 a 7,4 & 7,1 a 7,4 & 7,0 a 7,6 \\
\hline Oxigênio dissolv. (mg. $\mathrm{L}^{-1}$ ) & 2,4 a 4,5 & 1,3 a 1,9 & 1,1 a 2,1 \\
\hline Condutividade $(\mu \mathrm{S})$ & $540,8 \pm 264,5$ & $745,2 \pm 215,6$ & $569,9 \pm 167,4$ \\
\hline DBO Total (mg. $\left.\mathrm{L}^{-1}\right)$ & $285,1 \pm 116,9$ & $164,2 \pm 71,1$ & $98,9 \pm 77,5$ \\
\hline DBO Filtrada (mg. $\mathrm{L}^{-1}$ ) & $129,4 \pm 86,4$ & $105,5 \pm 46,6$ & $78,5 \pm 37,8$ \\
\hline DQO Total (mg. $\left.\mathrm{L}^{-1}\right)$ & $799,5 \pm 234$ & $472,3 \pm 134,4$ & $417,7 \pm 177,2$ \\
\hline DQO Filtrada $\left(\mathrm{mg} \mathrm{L}^{-1}\right)$ & $263,5 \pm 67,6$ & $187,8 \pm 33,3$ & $176,6 \pm 55,2$ \\
\hline Alc. Total $\left(\mathrm{mgCaCO}_{3 .} \mathrm{L}^{-1}\right)$ & $112,0 \pm 28,7$ & $246,8 \pm 37,2$ & $189,5 \pm 27,3$ \\
\hline Alc.Parcial $\left(\mathrm{mgCaCO}_{3} \mathrm{~L}^{-1}\right)$ & $76,1 \pm 22,5$ & $128,5 \pm 28,8$ & $124,5 \pm 23,3$ \\
\hline $\mathrm{ST}\left(\mathrm{mg} \cdot \mathrm{L}^{-1}\right)$ & $583,3 \pm 54,6$ & $402,3 \pm 40,9$ & $333,3 \pm 78,8$ \\
\hline $\mathrm{SST}\left(\mathrm{mg} \cdot \mathrm{L}^{-1}\right)$ & $298,1 \pm 92,0$ & $103,8 \pm 20,0$ & $72,8 \pm 38,9$ \\
\hline $\operatorname{SSV}\left(\mathrm{mg} \cdot \mathrm{L}^{-1}\right)$ & $152,3 \pm 86,0$ & $99,0 \pm 22,2$ & $68,8 \pm 31,1$ \\
\hline SSF $\left(m g \cdot L^{-1}\right)$ & $45,8 \pm 28,7$ & $14,8 \pm 6,9$ & $10,7 \pm 7,7$ \\
\hline Fósforo (mg. $\mathrm{L}^{-1}$ ) & $7,1 \pm 2,3$ & $30,6 \pm 6,2$ & $24,4 \pm 2,4$ \\
\hline Potássio (mg. $\mathrm{L}^{-1}$ ) & --- & $18,5 \pm 3,5$ & $18,5 \pm 3,5$ \\
\hline NTK (mg. $\left.{ }^{-1}\right)$ & $34,7 \pm 23,2$ & $58,2 \pm 18,7$ & $47,4 \pm 16,6$ \\
\hline N-Amoniacal (mg. $\mathrm{L}^{-1}$ ) & $15,6 \pm 6,9$ & $33,5 \pm 5,2$ & $30,9 \pm 10,1$ \\
\hline N-Nitrito (mg. $\mathrm{L}^{-1}$ ) & $0,3 \pm 0,1$ & $0,2 \pm 0,05$ & $0,2 \pm 0,1$ \\
\hline N-Nitrato (mg. $\mathrm{L}^{-1}$ ) & $0,1 \pm 0,05$ & $0,1 \pm 0,05$ & $0,1 \pm 0,05$ \\
\hline Coliformes Totais & $1,21 \times 10^{8}$ & $5,86 \times 10^{7}$ & $1,53 \times 10^{7}$ \\
\hline Escherichia coli & $6,76 \times 10^{6}$ & $4,79 \times 10^{6}$ & $1,04 \times 10^{6}$ \\
\hline Helmintos (organismos. $\mathrm{L}^{-1}$ ) & 24 a 54 & $0-22$ & $0-18$ \\
\hline Protozoários (organismos. L $^{-1}$ ) & $120-132$ & $12-36$ & $10-25$ \\
\hline
\end{tabular}

*Valores médios das aplicações.

As Figuras 7, 8, 9 e 10 apresentam as concentrações de DQO e DBO no perfil do solo, ao longo do ciclo da cultura do milho para as duas safras.

Os valores médios obtidos para os coletores de drenagem para DBO nas parcelas irrigadas com efluente indicam uma redução de cerca de $94 \%$ em relação ao efluente anaeróbio aplicado na irrigação e de $97 \%$ em relação ao esgoto bruto (Tabela 3 ), com os

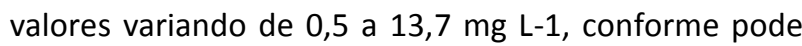
ser observado na Figura 7, e de 1,9 a 22,57 mg L-1, conforme pode ser observado na Figura 8. Observa-se que há uma tendência de queda da DBO ao longo do perfil do solo, resultante da decomposição dos compostos orgânicos incorporados ao solo via aplicação de efluentes.

Nota-se ainda centro declínio na concentração ao longo do perfil do solo.
Logo, em profundidades maiores foi observada concentração menor para a DBO.

Apesar do maior volume de efluente empregado na 1a safra (Tabelas 1 e 2), não há grandes variações nas concentrações entre as safras, o que demonstra que o solo possui boa capacidade de amortização e tratamento. Quanto à qualidade esperada do efluente tratado pelo método da irrigação, na 1a safra somente $35 \%$ dos resultados de DBO encontram-se

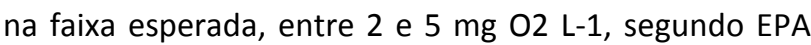
(1981). Já na $2 a$ safra $45 \%$ dos resultados de DBO encontram-se na faixa acima. Entretanto, é importante ressaltar também, que o solo natural possui partículas que garantem elevação do valor de DBO na análise do líquido lixiviado, como podemos observar nas parcelas irrigadas somente com água. 


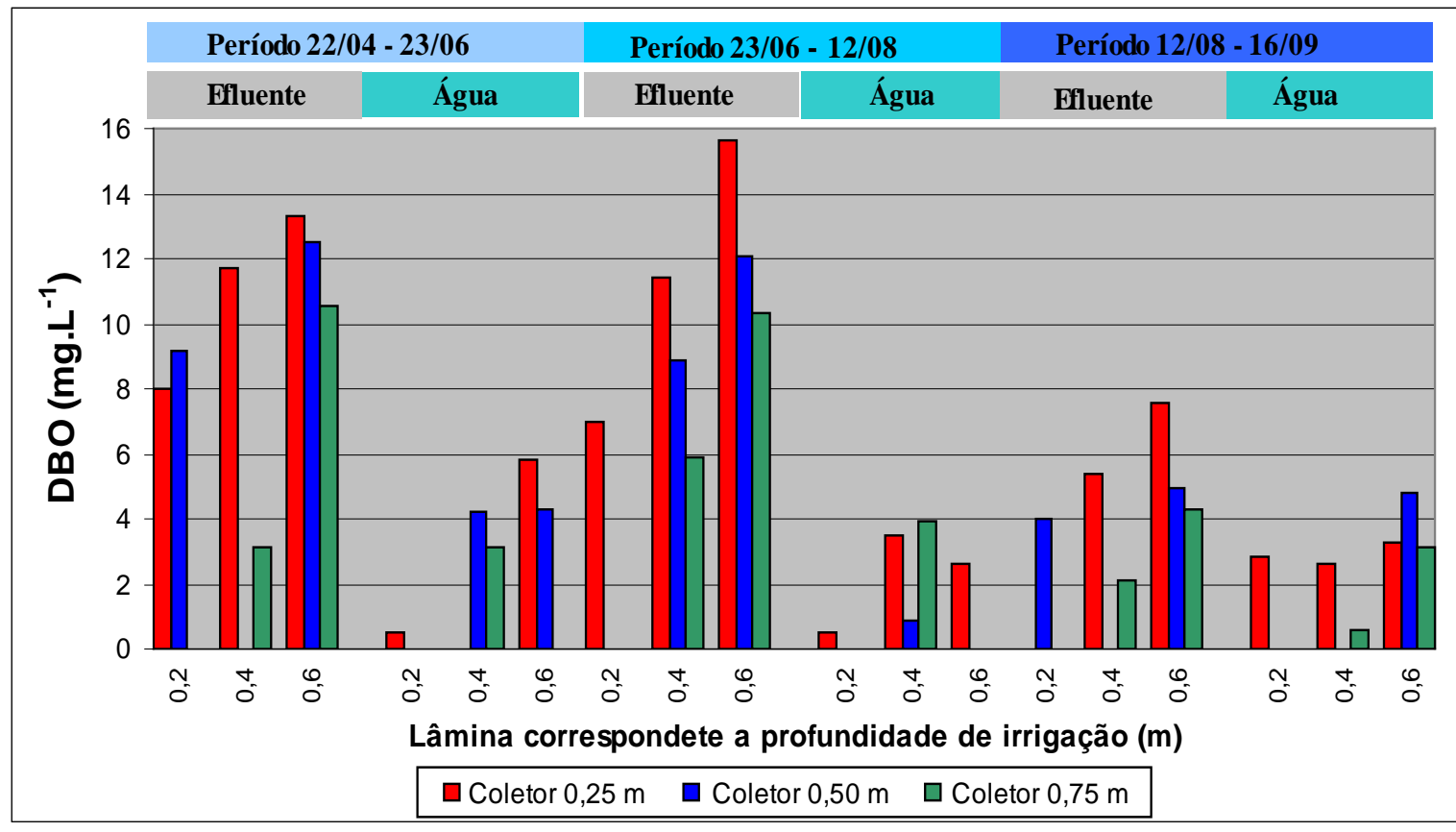

Figura 7: Valores de DBO (mg L-1) no perfil do solo e ao longo do tempo, nas parcelas de milho irrigadas com efluente anaeróbio, com lâminas de irrigação: 0,20; 0,40 e 0,60m (1a safra).

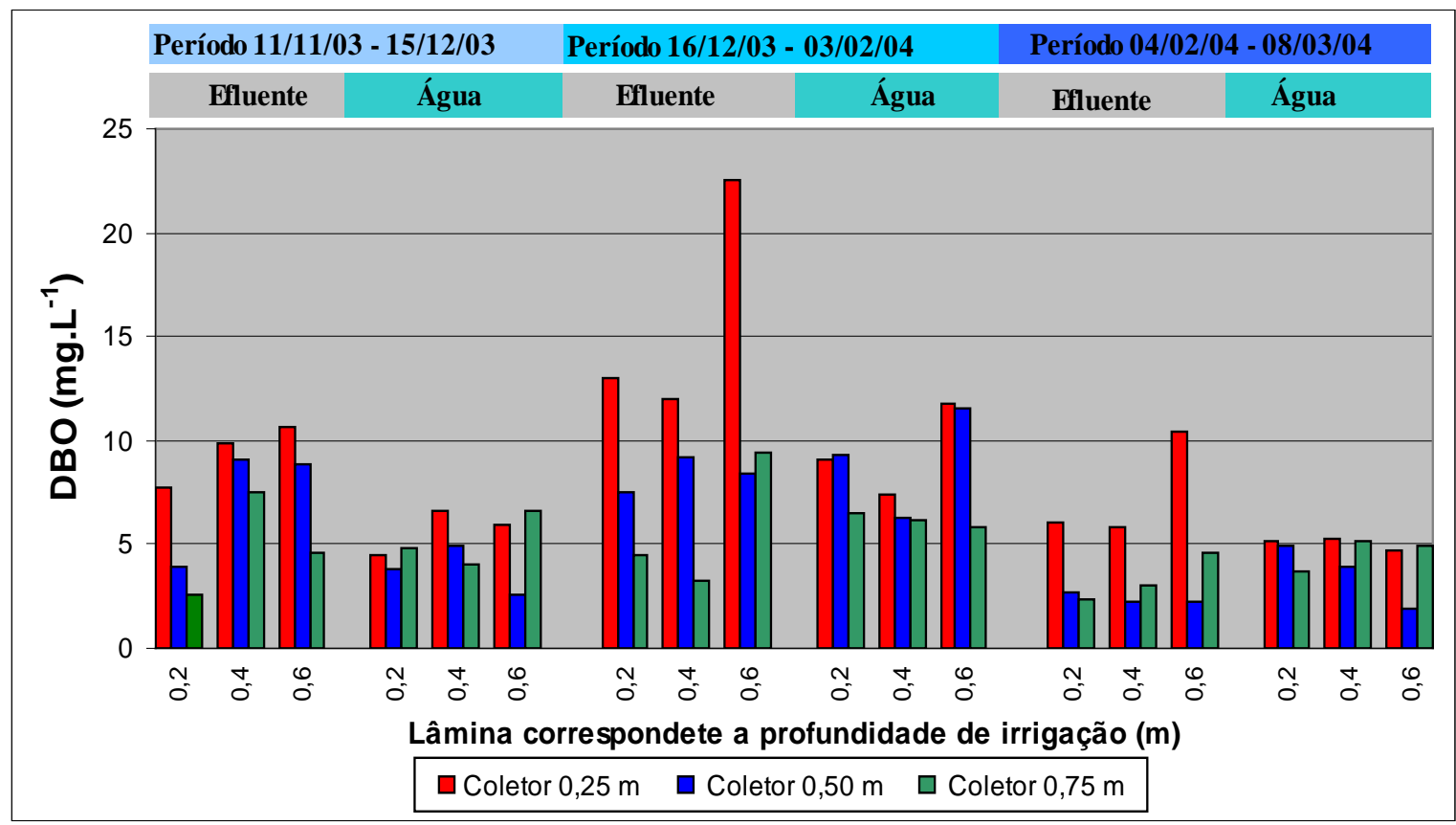

Figura 8: Concentrações de DBO (mg/L) no perfil do solo e ao longo do tempo, nas parcelas de milho irrigadas com efluente anaeróbio, com lâminas de irrigação: 0,$20 ; 0,40$ e $0,60 \mathrm{~m}$ ( $2^{\mathrm{a}}$ safra).

Para os valores médios de DQO, apresentados nas Figuras 9 e 10, observa-se uma redução de cerca de $91 \%$ na concentração das amostras dos coletores de drenagem em relação ao efluente anaeróbio, e de $95 \%$ em relação ao esgoto bruto. Analisando os valores apresentados para cada coletor de drenagem livre, observa-se uma tendência de queda da DQO para os coletores mais profundos. A priori, as lâminas hídricas de 0,40 e $0,60 \mathrm{~m}$ apresentaram concentrações maiores com relação à de $0,20 \mathrm{~m}$. Apesar do maior volume de efluente empregado na 1a safra, não há grandes variações nas concentrações entre as safras. 


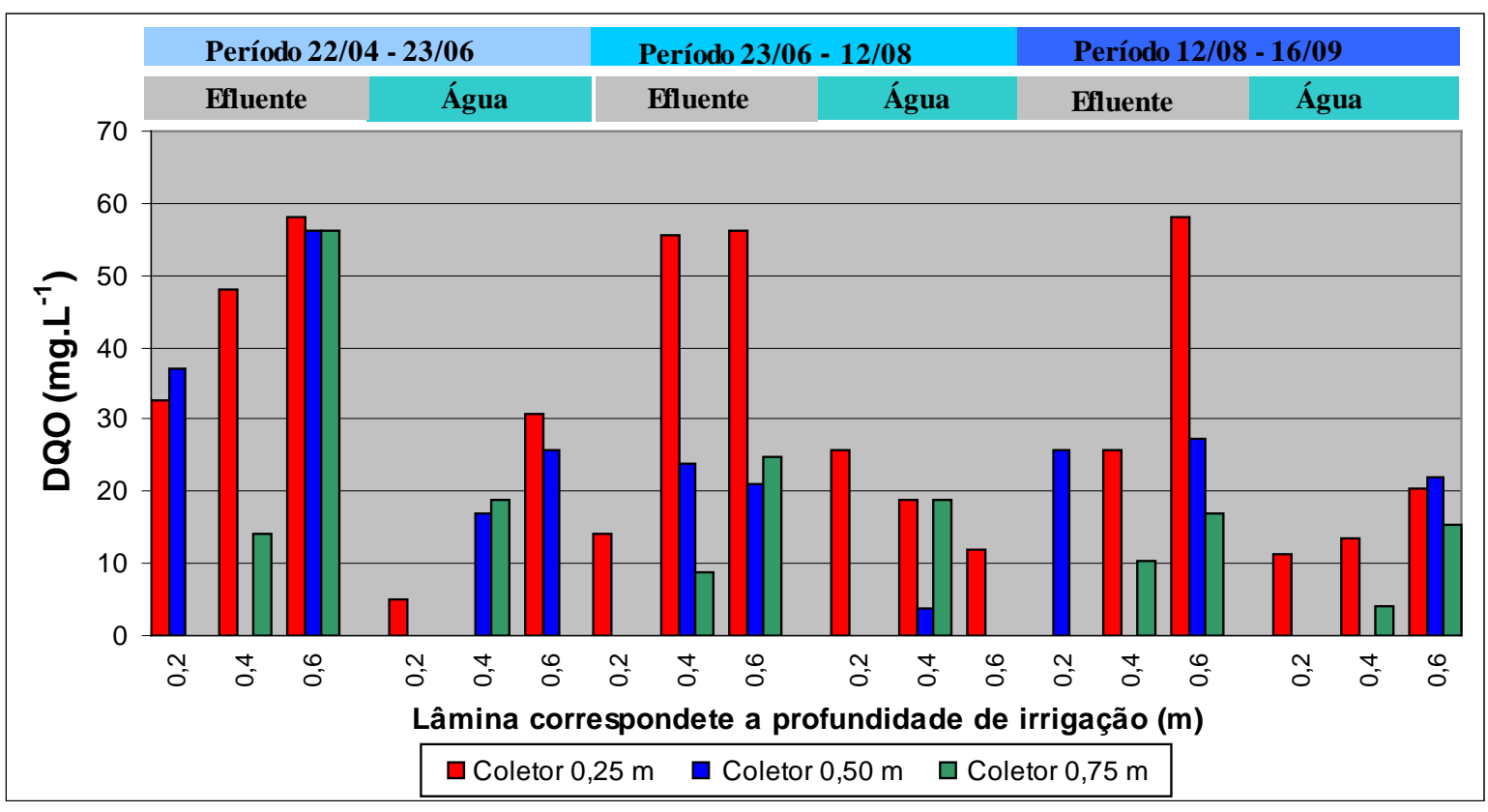

Figura 9: Valores de DQO (mg L-1) no perfil do solo e ao longo do tempo, nas parcelas de milho irrigadas com efluente anaeróbio, com lâminas de irrigação: 0,20; 0,40 e 0,60m ( $1^{\mathrm{a}}$ safra).

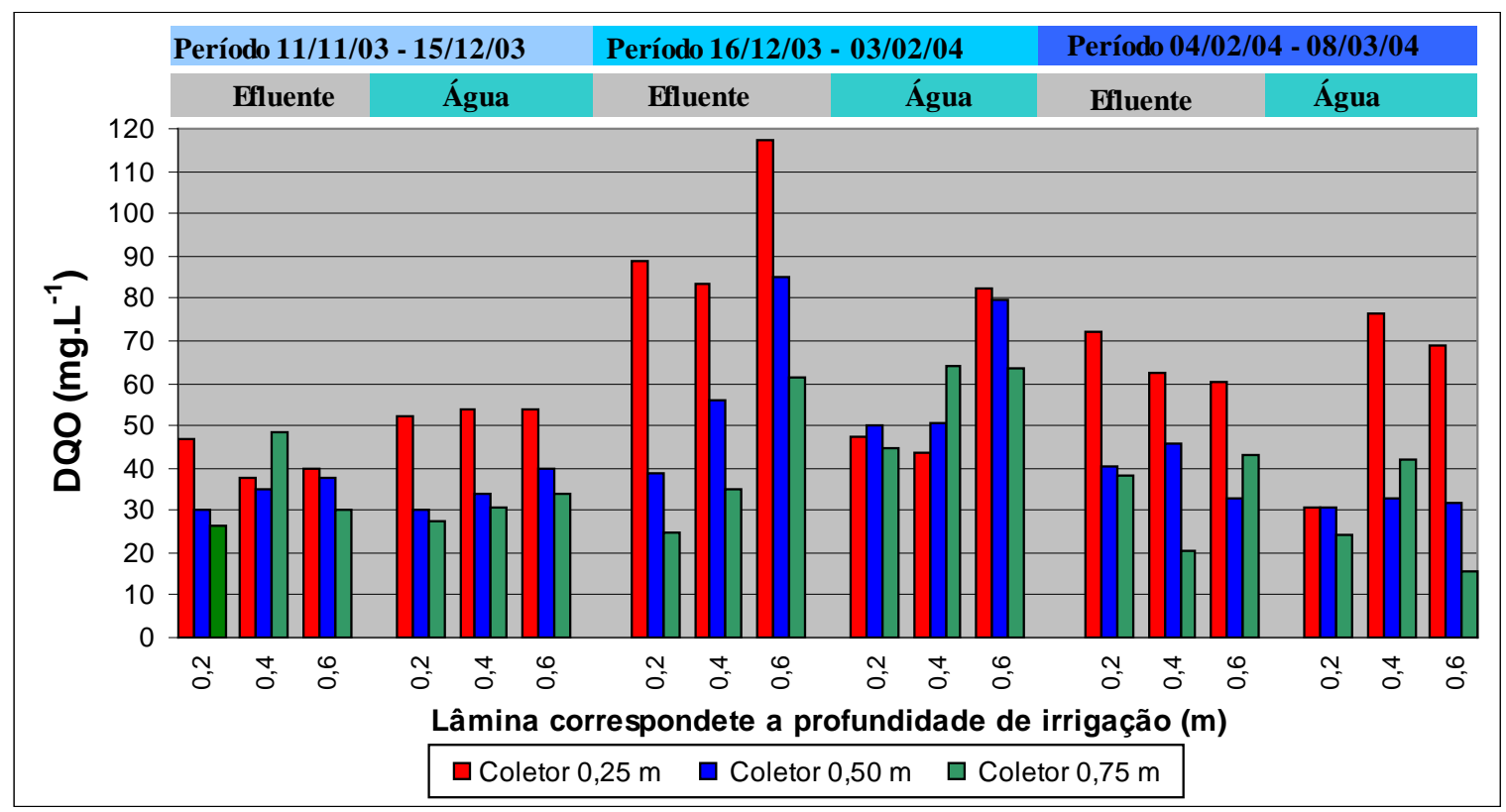

Figura 10: Valores de DQO (mg L-1) no perfil do solo e ao longo do tempo, nas parcelas de milho irrigadas com efluente anaeróbio, com lâminas de irrigação: $0,20 \mathrm{~m} ; 0,40 \mathrm{~m}$ e $0,60 \mathrm{~m}\left(2^{\mathrm{a}}\right.$ safra).

\section{CONSIDERAÇÕES FINAIS}

De acordo com as condições deste experimento, visando o pós-tratamento de efluentes domésticos tratados em lagoas anaeróbias em solo agrícola, pode-se concluir que:

- o pós-tratamento no solo é eficiente para redução da carga orgânica (DBO) do resíduo, assim como para redução dos valores de DQO;

- não foram observados riscos de contaminação do lençol freático, com os efluentes aplicados até a lâmina de $0,60 \mathrm{~m}$, neste tipo de solo;
- a menor absorção de $\mathrm{N}$ pela planta na fase de maturação dos grãos contribui para maior disponibilidade do elemento no perfil do solo e maiores riscos de lixiviação e contaminação do lençol freático.

- em períodos de maior intensidade de precipitação pode ocorrer maiores concentrações de carga orgânica no líquido lixiviado devido o carreamento de compostos de garantem DQO e DQO pela percolação da água de chuva. 


\section{REFERÊNCIAS BIBLIOGRÁFICAS}

BRASIL. Conselho Nacional do Meio Ambiente. Resolução CONAMA no 357 de 17 de março de 2005. Dispõe sobre a classificação dos corpos de água e diretrizes ambientais para o seu enquadramento bem como estabelece as condições e padrões de lançamento de efluentes, e dá outras providencias.

BRASIL. Ministério da Saúde. Portaria MS 518, de 25 de março de 2004. Procedimentos e responsabilidades relativas ao controle e vigilância da qualidade da água para o consumo humano e seu padrão de potabilidade, Brasília, 25 mar. 2004. DOU 26/03/2004, seção l, p. 266.

EPA, Environmental Protection Agency. The Use of Reclaimed Water and Sludge in Food Crop Production, 1992.

EPA, Environmental Protection Agency. Process Design Manual for Land Treatment of Municipal Wastewater. Cincinnati, 1981.

FRIEDLER, E. JEEZRAEL. Valley project for wastewater reclamation and reuse, Israel. Water Science and Technology. Volume 40, número 4, England: Elsevier Science Ltd., 1999. p347-354.

RAIJ, B. van; CANTARELLA, H.; QUAGGIO, J.A.; FURLANI, A.M.C. Recomendações de Adubação e Calagem para o Estado de São Paulo. 2.ed. Campinas: Instituto Agronômico Fundação IAC, 1996. 285p. (Boletim Técnico 100).

STANDARD METHODS FOR THE EXAMINATION OF WATER AND WASTEWATER. 19 ed. Washington: APHA; AWWA; WEF, 1995. 1082p.

VIEIRA, D.B. Curs Aprofitament Agrícola dels Recursos Hidrics de Les Conques. Solsona: Universitat de Lleida, 1999. 